\title{
Spatial Mobility, Migration, and Living Arrangements
}

\author{
Edited by Can M. Aybek, Johannes Huinink, and Raya Muttarak \\ Dordrecht: Springer, 2015 \\ ISBN 978-3-319-10021-0 \\ Hardcover C\$109.99, 254 pp.
}

\section{Reviewed by Barry Edmonston University of Victoria}

Most research publications are concerned with determinants or factors affecting an outcome, such as divorce or family stability. Other works focus on the consequences or implications of a factor or related processes, such as the effects of immigration on a population's ethnic composition. Less common is research that concerns the overlap of two distinct topics, which is the motivation of this book. It focuses on the intersection of the dynamics of spatial mobility and living arrangements. In a general way, the emphasis of this book is a subset of the interconnection of migration and life course events, a topic considered in the Spring/Summer 2013 special issue of Canadian Studies in Population (vol. 40, no. 1-2).

The overlap of spatial mobility and living arrangements is a useful area for systematic study. Causality in this relationship runs in both directions, to give two examples: (a) long-distance commuting affects family life, while (b) changes in family structure can influence spatial mobility. There are both positive and negative effects of spatial mobility. Positively, spatial mobility can reunite families and improve living conditions through higher income or access to better schools. On the other hand, negatively, some mobility strategies can worsen family life by separating family members or worsening conditions for some members when, for instance, a spouse moves for economic reasons but is away for long periods. Family dynamics influence spatial mobility in different ways as well. Families with young children may move to improve schooling opportunities. Divorced couples inevitably separate into two households. Aging parents often trigger mobility decisions for either the parents or their children, to improve proximity. Life cycle changes, in general, are associated with spatial mobility.

This volume's three editors are European: Aybek and Huinink are associated with Bremen University in Germany, and Muttarak is affiliated with the Vienna Institute of Demography in Austria. The ten empirical papers sometimes deal with more than one country. Overall, there are seven papers dealing with Germany, and one paper that includes data on Switzerland, Italy, United States, Spain, and Europe in general. Six papers examine new survey data, often collected by the authors. One research paper analyzes census microdata. And three papers discuss the results of ethnographic case studies.

This edited volume includes a useful 19-page introduction (chapter 1) and ten empirical papers that are organized in three sections. The first section includes three papers (chapters 2 to 4 ) related to the relationship of partner choice and family formation with international migration. Chapter 2 examines the partner selection and migration from Turkey by Turkish immigrants living in Ger- 
many. It discusses the motivations and risks for both partners, and how key problems for transnational marriages are negotiated and resolved. Chapter 3 deals with partner choices for second generation Turkish women in Switzerland. The Swiss research primarily summarizes twenty-six interviews with men and women, with an emphasis on how families influence their children's decisions. Chapter 4 discusses results from a mail questionnaire in Berlin concerning fertility levels for German husbands with a foreign-born wife (limited in the survey to wives from Poland, Thailand, Russia, or Brazil). The fertility level of these transnational unions is lower than German-German unions, because immigrant women in transnational marriages are older at the time of their German marriage and sometimes have children from prior marriages.

The second section includes three papers (chapters 5-7) dealing with job-related migration and family arrangements. Recurring spatial mobility includes migration as well as daily commuting. But, as Chapter 5 points out, a new form of mobility is frequent long-distance daily and weekly commuting associated with high-speed transportation. The higher speed of recent train transportation systems in Europe and other places means that more people can work and live at longer distances and commute rather than relocate. Long-distance commuting, however, has social consequences for commuters, and their families and communities. Viry and Vincent-Geslin analyze 2007 survey data on 6,128 households in six European countries, noting three types of recurring long distance commuting: (1) long-distance daily commuting of two or more hours; (2) long-distance family relationships where one partner lives more one hour driving from their partner; and (3) overnighters who spend 60 or more nights a year away from their partner, in a second home, on business trips, or in seasonal work. It may be surprising that about one-in-five European households with one working partner reports that they are engaged in recurring long-distance commuting, with 36 per cent in type (1), 5 per cent in type (2), 25 per cent in type (3), 17 per cent in two or more types, and the remaining unable to be classified in one of the three types above. This suggests that recurring long-distance commuting should be an important topic of study. Research in chapter 5 argues that mobility commuting may be adaptive but does not provide evidence about mobility preferences over the life course. Do younger families involved in mobile living continue this lifestyle over time? Do both partners and their children report similar experiences, perceptions, and preferences about mobile living? Chapter 5 should serve as a stimulus for further research on the social effects of long-distance commuting.

Chapter 6 concerns the relationship of commuting to partnerships, comparing couples living apart together with those living together apart. Overall, partnership satisfaction for German couples is higher for those living together, while those living apart together appear more satisfied than those living together apart. Chapter 7 examines the effect of job-related mobility on union dissolution, based on a German longitudinal survey. Interestingly, long-distance commuting does not increase the risk of separation, and female employment does not increase the risk of separation, but lengthy commuting of working women does decrease partnership stability. The author proposes that female fulltime employment requiring long-distance commuting becomes a risk in Germany when it puts too great a burden on women, perhaps because such commuting conflicts with childcare and other family duties.

The third section includes four papers (chapters 8-11) describing spatial mobility and family life course events. Chapter 8 compares living arrangements for immigrant and native-born young adults in Spain and the United States. The authors find that living arrangements differ by nativity, and that living arrangements for young immigrants vary by age at arrival, country of origin, and also by country of destination. Chapter 9 reports on an ethnographic study based on interviews with university students in Italy and Germany, asking about their motivation and reasons for moving from their parents' home. Italian students are less likely to seek residential independence, while 
German students suggest that employment conditions are an important reason to move away from their parents. Scheir's work in chapter 10 concerns the spatial mobility of families following divorce, a topic that has received relatively little research. Her analysis of survey data, along with an ethnographic case study of German families, offers insights about the spatial processes and suggests needed further work. The final chapter in the book, chapter 11, deals with spatial mobility during pre- and post-retirement for German adults aged 50 years and older. They analyze longitudinal data from the German Socio-Economic Panel, which has interviewed a large number of adults since 1984 in West Germany and since 1990 in East Germany. Their piecewise-constant hazard model analysis finds that employment changes, housing conditions, and family-related transitions are key to understanding the decision about when and where to move. Their results will interest other researchers, because German survey data includes several variables — such as health conditions, disability changes, and loneliness - that are often not available in other data.

In sum, this edited volume is an important book for those studying migration and family structure. The ten empirical studies cover a range of important topics that will surely stimulate interest in research on spatial mobility and living arrangements. 